\title{
Ethical Challenges Come Home
}

\author{
Matthew K. Wynia, MD, MPH and James E. Sabin, $M D^{2}$ \\ 'Institute for Ethics, American Medical Association, Chicago, IL, USA; ${ }^{2}$ Harvard Pilgrim Health Care, Boston, MA, USA.
}

$\mathrm{J}$ Gen Intern Med 28(1):9-11

DOI: $10.1007 / \mathrm{s} 11606-012-2232-0$

(c) Society of General Internal Medicine 2012

$\mathrm{T}$ he patient-centered medical home (PCMH) is becoming a Rashomon-like touchstone for how health system reforms are expected to affect primary care. While PCMH pilot programs nationwide are serving as test cases for how reforms might play out, primary care advocates also tend (a) to see in them the ideals we want to see, and (b) to not see some ways they might challenge us. ${ }^{1}$

In a position paper in this month's Journal, ${ }^{2}$ the American College of Physicians (ACP) Professionalism, Ethics and Human Rights Committee begins to address these issues, opening a crucial conversation by asking the question: Does the PCMH promote Beauchamp and Childress' four core principles of medical ethics (namely: respect for autonomy, beneficence, nonmaleficence and justice)? $?^{3}$

To answer this question, the Committee compared the Joint Principles of the Patient Centered Medical Home, developed by the ACP and several other primary careoriented specialty groups, ${ }^{4}$ and a similar set of "key attributes" of patient-centered primary care, with the four principles of medical ethics. Their answer is a qualified, but still loud, "Yes!" In particular, they note that patient engagement in care decisions and patient-centeredness more generally (two sine qua non features of an ideal PCMH) are directly supportive of autonomy, beneficence and nonmaleficence. A third PCMH feature, access to a personal physician, is seen as supporting the ethical requirement that physicians seek to ensure access to care for all, a derivative of the principle of justice. Finally, the PCMH focus on systematic efforts to improve safety and quality is recognized as supporting nonmaleficence and beneficence.

It is not surprising that the authors conclude the PCMH is largely consistent with Beauchamp and Childress' four principles. After all, the Joint Principles read very much like a list of general principles for excellent medical practicemedical care in any setting is better when it is patientcentered, safe, easy to access, engages patients in care decisions, exchanges information readily, continuously improves quality, and so on. So the PCMH, as a concept defined by these aspirational principles, is bound to support the traditional four principles of biomedical ethics.

Published online September 28, 2012
We propose to extend the Committee's analysis in two ways. First, the rubber hits the road when broad principles are used to guide practical decisions. There are ethical implications in defining what comprises a $\mathrm{PCMH}$, measuring its success, and paying for its implementation. Second, ethical analyses based on principlism don't always force us to ask the toughest questions about our own contributions to ethical problems. Specifically, as Arend et al. have noted, the transformation to $\mathrm{PCMH}$ practice forces physicians to develop "new mental models of patient care." Our own willingness to accept the deeply challenging implications of adopting PCMH ideals in our professional lives might prove the highest hurdle of all.

\section{ETHICS AND IMPLEMENTATION}

It is a truism that good ethics begins with good facts. This being the case, the first ethical question that must be addressed is: Does the PCMH model actually work to achieve better care and better health at sustainable cost? If the answer to this question is no, then any subsequent ethical questions are moot.

Fortunately, early results are promising, with some sites showing reduced patient emergency department visits and hospitalizations, ${ }^{6}$ and improved patient empowerment and satisfaction. ${ }^{7}$ One insurer recently reported a significant positive return on investment. ${ }^{8}$ A review in 2010 concluded that "investing in primary care patient centered medical homes results in improved quality of care and patient experiences, and reductions in expensive hospital and emergency department utilization." 9 In one study, levels of clinicians' emotional exhaustion in a PCMH practice was significantly reduced compared to levels at two control clinics $(14 \%$ vs. $35 \%, p<0.001){ }^{7}$ While reducing clinician burnout isn't a national "triple aim" goal per se, ${ }^{10}$ if PCMH practices are shown to improve professional fulfillment that would be an important mark in their favor.

Not all studies have been so positive, however. A large national demonstration project saw only small or no changes in clinical and cost outcomes, ${ }^{11}$ and one survey of demonstration projects concluded that "a majority...did not have well-developed evaluation plans." ${ }^{\text {12 }}$ Early work also suggests the financial costs of practice transformation are quite high, and might remain so for some time, making 
sustainability a major concern unless more payers are willing to make contributions. ${ }^{6}$

A related problem is determining what counts as a $\mathrm{PCMH}$. The ACP Committee elected to use the Joint Principles to define the PCMH, but how does one measure adherence to these principles? The National Committee on Quality Assurance (NCQA), ${ }^{13}$ The Joint Commission (TJC) ${ }^{14}$ and the Utilization Review Accreditation Commission (URAC) ${ }^{15}$ each have different ways of assessing adherence, and all approach the PCMH transformation as a journey more than a destination. Measuring outcomes associated with adoption of the PCMH model is complex when adoption isn't all-ornone. For example, as the ACP position paper notes, some measures of whether a practice is a PCMH emphasize adoption of electronic records and practice design features more than patient-centeredness measures.

An additional ethical challenge with regard to $\mathrm{PCMH}$ implementation is the matter of equity. Who should pay for the infrastructure of the PCMH? A typical primary care practice will see patients covered by a wide array of payers. In one $\mathrm{PCMH}$ demonstration project, more than 1,000 different employer-based plans covered patients who received PCMH care, but only a few provided any funding for these enhanced primary care functions. ${ }^{6}$ On average, only $20 \%$ of patients were covered by plans that contributed to developing the PCMH infrastructure; the rest were freeriders. Is it fair that all payers and patients derive benefits from $\mathrm{PCMH}$ structures and processes that only some are paying to support? Given the massive cultural and structural transformation necessary to become a PCMH, it would not be feasible to exclude certain patients and plans within a practice from receiving $\mathrm{PCMH}$ care, but doing so would also raise ethical problems, since many patients don't get to choose their insurer

\section{TAKING A HARD LOOK IN THE MIRROR}

Even more ethically challenging is the fact that some aspects of implementing a PCMH require fundamental changes in how we, as physicians, see ourselves, our work, and our relations with patients and colleagues. Nutting et al., examining the first national demonstration project on practice transformation to a $\mathrm{PCMH}$, wrote that the shift "requires a transformation, not an incremental change ... [affecting physicians'] sense of identity, and imagination about the meaning of patient care."16 Full adoption of the PCMH means embracing team-based, patient-centered care, which is "not solely a matter of added resources and new technology." As Nutting et al. note, "whole practice redesign is different from incremental quality improvement." ${ }^{\text {"16 }}$ Effective doctoring in the transformed care environment of a $\mathrm{PCMH}$ requires a fundamental reexamination of roles, responsibilities, and relationships.
The place where this might be most apparent is in language about "leadership" of the PCMH. The notion that a PCMH must be "physician-led" is central to the Joint Principles, but this has not been a required criterion for PCMH recognition by accrediting bodies. In fact, the idea of "nurse-led" medical homes has taken on political and economic momentum, with a number of these practices receiving NCQA accreditation using NCQA's "Physician Practice Connection ${ }^{\text {TM" }}$ criteria. ${ }^{17}$

In a recent discussion paper, an Institute of Medicine (IOM) Working Group noted that within high-functioning health care teams, leadership roles are clear but fluid and usually depend on the specific task at hand. ${ }^{18}$ More specifically, "leadership" did not mean having a single person rule over all other members of the team. The authors of the IOM paper note that "being an effective team leader for a particular task (like running a team meeting) can require a set of skills that are distinct from those required for making clinical decisions."18 As a result, "physicianled" seems an antiquated, or at least needlessly provocative, term in the context of team-based care. (By the same token, the notion of "independent practice" by nurse practitioners or anyone else - including physicians — seems equally antiquated within high-functioning teams.)

Finally, perhaps the most difficult ethical challenge is grappling with the fundamentally changed relationship between clinicians and patients in the PCMH. For clinicians, patient-centered and team-based care requires a massive shift in the "roles of individuals and the practices, sense of identity, and imagination about the meaning of patient care."16 To put it bluntly, ethical patient-centered care aims to put patients, not physicians, in charge. This raises significant questions about the roles of patients as members of teams, not merely as the objects of a team's attention. $^{19}$ It means increased patient engagement in teamwork and demands more clarity regarding patients' roles on teams, including their responsibilities.

In the ACP position paper, this final point surfaces as a stark declaration that "It is ethically inappropriate to make the level of patient engagement a precondition for access or provision of benefits." 2 But, properly understood, the transformation to a $\mathrm{PCMH}$ intends to fundamentally alter the traditional view of medical care as comprising "benefits" that clinicians "deliver" and patients "receive." In other words, the truly radical transformation inherent in the PCMH is that clinicians, patients and others live in these homes together, the homes exist in a neighborhood, and everyone is working together to achieve optimal health outcomes. The relationships, like those in a family home, are fully reciprocal and rarely, if ever, unidirectional.

If this vision for patients and clinicians as cohabitating in the medical home is actually fulfilled, then the idea that patient "engagement" could be a precondition for "provision of benefits" will not merely be unethical, it will be 
nonsensical. By bringing such considerations to the fore, the ACP Committee has opened an important ethical, clinical and sociological conversation. not only about the PCMH but, at the deepest level, about the very meaning of life as a doctor in the medical home of the future.

Disclaimer: The views expressed are those of the authors and should not be ascribed to the American Medical Association or any other organizations with which the authors are affiliated.

Corresponding Author: Matthew K. Wynia, MD, MPH; Institute for Ethics, American Medical Association, 515 N State St, Chicago, IL 60654, USA (e-mail: matthew.wynia@ama-assn.org).

\section{REFERENCES}

1. Marmor T, Oberlander J. From HMOs to ACOs: the quest for the Holy Grail in U.S. Health Policy. J Gen Intern Med. 2012;27(9):1215-8.

2. Braddock CH, Snyder L, Neubauer RL, Fischer GS, For the ACP Ethics, Professionalism and Human Rights Committee and the SGIM Ethics Committee. The patient-centered medical home: an ethical analysis of principles and practice. J Gen Intern Med. 2013. doi: 10.1007/s11606-012-2170-x.

3. Beauchamp TL, Childress JF. Principles of Biomedical Ethics. 5th ed. New York: Oxford University Press; 2001.

4. American Academy of Family Physicians (AAFP), American Academy of Pediatrics (AAP), American College of Physicians (ACP), American Osteopathic Association (AOA). Joint Principles of the Patient Centered Medical Home. 2007. Available at: http://www.pcpcc.net/content/jointprinciples-patient-centered-medical-home Accessed September 7, 2012.

5. Arend J, Tsang-Quinn J, Levine C, Thomas D. The patient-centered medical home: history, components, and review of evidence. Mt Sinai $J$ Med. 2012;79:433-50.
6. Harbrecht MG, Latts LM. Colorado's Patient-Centered Medical Home Pilot met numerous obstacles, yet saw results such as reduced hospital admissions. Heal Aff. 2012;31(9):2010-7.

7. Reid RJ, Fishman PA, Yu O, et al. Patient-centered medical home demonstration: a prospective, quasi-experimental, before and after evaluation. Am J Manag Care. 2009;15(9):e71-87.

8. Raskas RS, Latts LM, Hummel JR, et al. Early results show WellPoint's Patient-Centered Medical Home pilots have met some goals for costs, utilization, and quality. Heal Aff. 2012;31(9):2001-9.

9. Grumbach K, Grundy P. Outcomes of Implementing Patient Centered Medical Home Interventions: A Review of the Evidence from Prospective Evaluation Studies in the United States. November 16, 2010. Available at: http://www.pcpcc.net/files/evidence_outcomes_in_pcmh.pdf Accessed September 7, 2012

10. Berwick DM, Nolan TW, Whittington J. The triple aim: care, health, and cost. Heal Aff. 2008;27(3):759-69.

11. Jaen CR, Ferrer RL, Miller WL, et al. Patient outcomes at 26 months in the Patient-Centered Medical Home National Demonstration Project. Ann Fam Med. 2010;8(suppl 1):s57-67.

12. Bitton A, Martin C, Landon BE. A nationwide survey of patient centered medical home demonstration projects. J Gen Intern Med. 2010;25 (6):584-92.

13. National Committee for Quality Assurance. NCQA Patient-Centered Medical Home. 2011. Available at: http://www.ncqa.org/Portals/0/Programs/ Recognition/2011PCMHbrochure_web.pdf Accessed September 7, 2012.

14. The Joint Commission. Primary Care Medical Home. Available at: http:// www.jointcommission.org/accreditation/pchi.aspx Accessed September 7, 2012.

15. URAC Patient Centered Health Care Home Program. Available at: https://www.urac.org/pchch/ Accessed September 7, 2012.

16. Nutting PA, Miller WL, Crabtree BF, et al. Initial lessons from the first national demonstration project on practice transformation to a patientcentered medical home. Ann Fam Med. 2009;7(3):254-60.

17. Scudder $\mathbf{L}$. Nurse-led medical homes: current status and future plans. MedScape, posted May 27, 2011. Available at: http://www.medscape. com/viewarticle/743197 Accessed September 7, 2012.

18. Mitchell P, Wynia M, Golden R, et al. Core principles and values of effective team-based care. Available at: www.iom.edu/tbc. [Note: this link will go live on October 2].

19. Wynia MK, Mitchell PH, VonKohorn I. Challenges at the intersection of team-based and patient-centered care. Insights from an IOM Working Group. JAMA. 2012 (in press). 